\title{
Development Of Business Intelligence On Enterprise Resource Planning For Business Small And Medium
}

\author{
Aulia Fitrul Hadi , Randy Permana \\ Universitas Putra Indonesia YPTK Padang, Indonesia \\ fitrulhadi@upiyptk.ac.id
}

\begin{abstract}
Small and Medium Enterprises (SMEs) are business sectors that are the foundation of the real sector of the Indonesian economy.SMEs are currently experiencing considerable challenges both from the internal in the form of quality and continuity products and external challenges since the enactment of the ASEAN-China Free Trade Agreement (ACFTA), where automotive manufacturing products from China enter the Indonesian market freely. In the competition open and competitive like this, the use of information technology is an urgent need for SMEs to be able to compete and increase business capacity. Use of Enterprise Resource Planning (ERP) in the manufacturing sector SMEs, is an information system that supports daily transactions and operations in managing company resources in an integrated manner, including: funds, people, machinery, spare parts, time, material, capacity, even method. Cross-functional integration capabilities in ERP provide overview of the flow of information on people, goods and services in real time. But a manager companies need not only transactional information, but also require fast data easy to understand to support decision making. This study aims to develop an intelligence business application that is service-reusable for integration, analysis and monitoring the performance of an SME in the manufacturing industry sector. Application development starts with do analysis on transactional data, and do the design of analytic applications provide a decision-making process with time-based access from various data sources, use ETL (Extract-Transform-Load) and graphical data display. The final results of this study describe the relationship between BI processes and modules on ERP and their use for SMEs in helping to map the company's potential and support business decision making.
\end{abstract}

Keywords: business intelligence, data warehouse, ERP, SMEs, automotive manufacturing, ETL

\section{Introduction}

Amid open and highly competitive competition, the use of information technology is an urgent need for Small and Medium Enterprises (UKM) to be able to compete and increase business capacity. Information technology and systems are needed primarily to see opportunities and information from various company resources that will be used to support decision making by the management of SME managers.

Some SMEs have used Enterprise Resources Planning (ERP) systems, especially in the automotive manufacturing sector. ERP system is a terminology given to information systems that support day-to-day transactions or operations in integrated management of company resources. The managed resources include funds, people, machinery, parts, time, material, capacity, even methods. ERP system integration is cross-functional and across units, so that it provides an overview of the flow of information on goods, finance, human resources and services in a company in real time (Kumar \& Hillegersberg, 2000; in Govindaraju, 2002). This results in flexibility and speed of the system in managing the development of supply and demand. ERP systems are generally divided into several inter-integrated subsystems such as financial systems, logistics systems, procurement and purchasing systems, production systems, sales and distribution systems. This system provides consistency and transparency for the 
entire enterprise so as to provide access to reliable and integrated information (Esteves \& Pastor, 2001; Botta-Genoulaz \& Millet, 2006).

However, the application of the transactional information system level such as ERP has limited ability to provide more meaningful data for the company. Transactional and operational data contained in a manufacturing company are very complex and have different meanings. To be able to see in terms of business so you can monitor business history, knowing the latest data and business, and determining future plans that are more profitable for the company, so the application that can map data and process it into data that has more "meaning" will be needed. A manager or company executive in the analysis process requires data that is fast and easy to understand to support the right decision making in adjusting to changing business needs.

Business Intelligence (BI) is an application that is used to facilitate the process of analysis and monitoring of companies in overcoming these problems. According to (Henry, 2006, in Kusnawi 2010), analytical applications are applications that provide a decision-making process with time-based access from various data sources. The majority of BI applications are currently built with service oriented as a form of solution in handling changes in business needs. The application of BI applications that are integrated with management applications such as ERP by implementing service-oriented architecture is one solution that can be used to overcome the limitations of management capabilities within the company. BI technology capabilities, namely to collect, store, analyze and provide access to data to help users make accurate decisions by carrying out various activities including decision support systems. An ERP system that is integrated with BI applications can continuously increase its competitive advantages.

This study aims to develop a service-reusable BI application to integrate, analyze and monitor the performance of SMEs in the manufacturing industry sector that uses ERP in general financial, sales, purchasing, and production processes. In table 1 describes the application modules that will be designed in this study and their uses for SMEs in the manufacturing industry. Table 1 Functional Description of ERP-based BI Systems for SMEs in the Manufacturing Sector (see attachment). Among the not optimal adoption of enterprise applications used at SME scale companies today is the limited application that exists in the aspect of information integration and its ability to conduct information analysis. Analysis of this information is needed to help make management decisions fast and accurate by looking at the internal and external dynamics of the company. Integration of information and the ability to conduct analysis will build the competitive advantage of SME companies amid competition in the era of free trade.

Integrated information becomes useless when the information analysis process does not work, and vice versa for analyzing information needed data integration. ERP is an application that is used to integrate business processes in a company, which usually consists of finance, purchasing, sales, production, and HR modules. While BI is an application that is used to simplify the process of analysis and monitoring of companies so as to facilitate and accelerate the company's strategic decision making process. BI is well built on complete and integrated transaction data or in other words BI is built on an ERP system. To optimize the ERP system as a transactional information system a decision support information system is needed such as BI applications, collaboration between these two types of applications on the SME scale will 
improve the performance and competitiveness of SME companies. An ERP system that is integrated with BI applications can continuously build SME competitive advantage. For example, the results of a BI solution can make the SME purchasing department find a price pattern, so that it can design a more competitive price by managing the purchasing process effectively and efficiently. The procurement department can immediately carry out a procurement process with $\mathrm{BI}$ alerts so as to minimize the inventory process but maximize the response to the customer

\section{Research Method}

In Figure 1, it is explained that among the currently not optimal applications used in SME scale companies are the limitations of applications that exist in the aspect of information integration and its ability to carry out information analysis. Analysis of this information is needed to help management decisions quickly and accurately by looking at the internal and external dynamics of the company. Integration of information and the ability to conduct analysis will build the competitive advantage of SME companies amid competition in the era of free trade

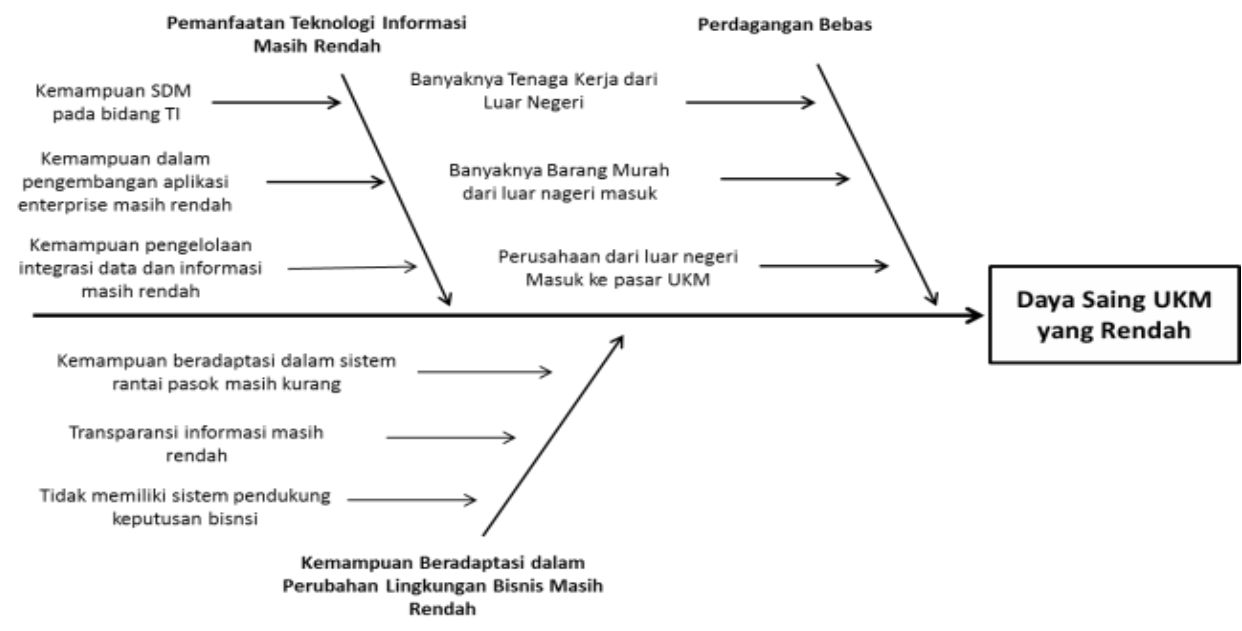

Figure 1 Fish Bone SME Competitiveness Chart

\subsection{Business Intelligence For Small And Medium Enterprises}

he BI architecture design model for SMEs is Independent Data Marts Architecture, as shown in figure 2. This architecture was chosen based on the consideration that this architecture is most appropriate, in accordance with the needs of SMEs to map the needs of one department, describing data requirements according to each department's department an UKM. Utilization of the Independent Data Marts architecture is quite flexible for SMEs, because interdependence between departments is not so rigid that each part can design and provide Data Mart according to the needs of their respective departments. 




Figure 2 Independent Data Mart Architecture

This architectural model describes flow data in a system consisting of:

a) Data Source, containing operational transaction / data data that is in the OLTP database (on line transaction processing) in SMEs. The table in the data source will be continued into the ETL process, which will then be used in the Data Mart. Supporting information needs to support SME performance include:

1) Sales Intake, information generated to support analysis of selling intakes related to targets to be achieved and revenues generated, based on categories, packages, per-time.

2) Product trends, resulting in analysis such as: growth and trend of a product, per-package, pertime, which can help SMEs in determining product marketing strategies.

3) Sales Performance, an analysis that can be generated from sales performance, includes the ability of the staff staff performance in processing respondents' data in following up so that it becomes the intake. Reports are generated on a per-package basis, per-total_ respondent, perfollow_up, per-capacity, per-intake, per-time based on each sales staff.

b) Extract - Transform - Load (ETL), the specified Data Source will be continued into the ETL process so that the data can be used according to later requirements. The data on OLTP will then be transformed into OLAP (on line analytical processing). The following is an overview of the ETL process carried out:

1) Extract, the process of retrieving data needed from various database tables in the data source that will be included in the Data Mart.

2) Transformation, the process of changing the data extracted into the data structure that will be used and according to the specified standards.

3) Load, the process of sending data that has been transformed into the final repository / Data Mart.

c) Independent Data Mart, a database that holds data that has undergone ETL processes, then the data will be loaded into a schema structure that has been determined based on user needs to be used in BI applications.

d) OLAP CUBE, data on Data Mart is prepared to be transformed into a multidimensional form so that it can be used by the user to help analyze.

e) End User Access and Applications, users who will access data in the data mart use applications that help them analyze these data, such as BI applications that can help support top management in making business decisions. 


\subsection{Extract-Load-Transform (ETL)}

Process To display information needed by a branch manager, a data source at the UKM Center that has been determined, then the data is carried out ETL process to enter data into the data mart. Following is the description of ETL Dataflow Diagram as shown in Figure 3.

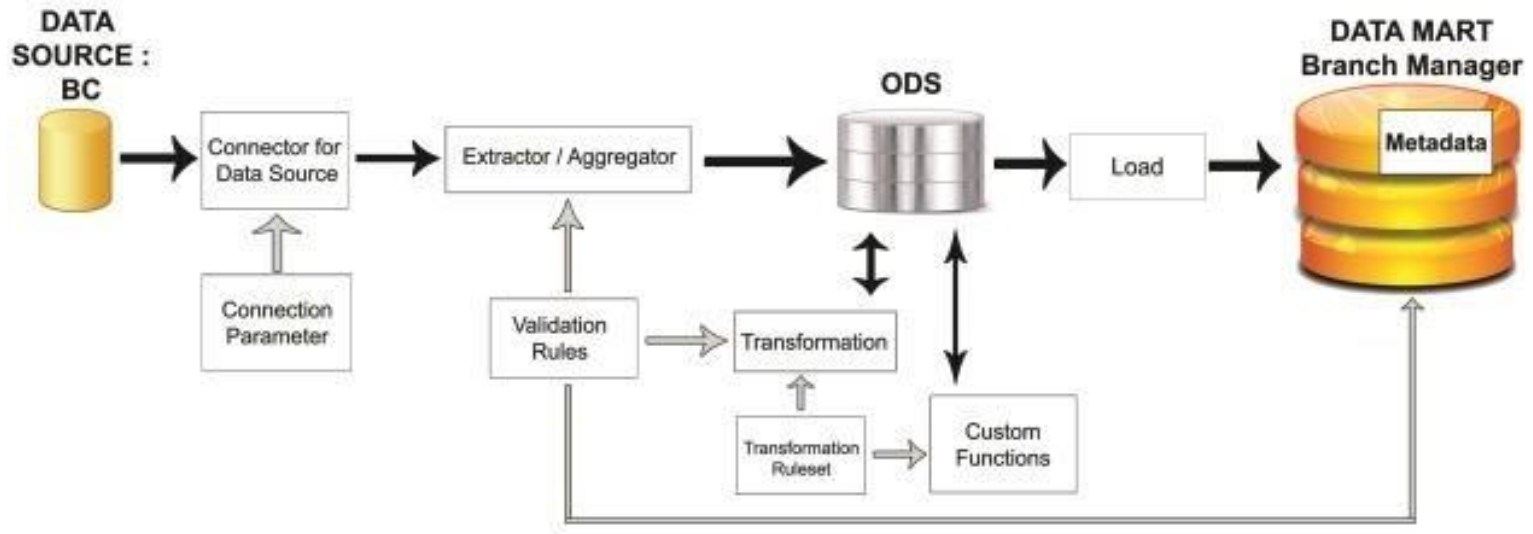

Figure 3 ETL Dataflow Diagram

Setiap tabel harus diberi judul singkat dan berurutan (nomor). Menempatkan mereka sedekat mungkin dengan bagian yang relevan dari teks. Hindari menggunakan warna kecuali diperlukan untuk interpretasi yang tepat dari gambar Anda.

\section{Build a Star Scheme}

tar schemes are used as logical design techniques for structuring data so that users can easily query quickly according to business needs (Inmon, 2005). Star schemes are made in the relational data model, this model connects between fact and other dimensions that are needed, for example for sales analysis, the fact is transactions that occur in sales and dimensions in the form of products, promotions, sales, etc., as in Figure 4.

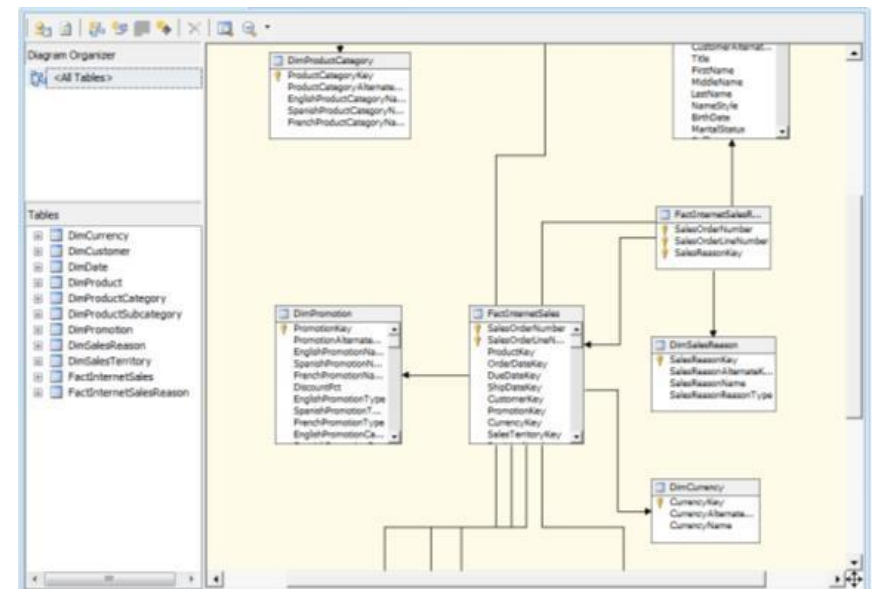

Figure 4 ETL Dataflow Diagram 
Star schemes are used as logical design techniques for structuring data so that users can easily query quickly according to business needs (Inmon, 2005). Star schemes are made in the relational data model, this model connects between fact and other dimensions that are needed, for example for sales analysis, the fact is transactions that occur in sales and dimensions in the form of products, promotions, sales, etc., as in Figure 4.

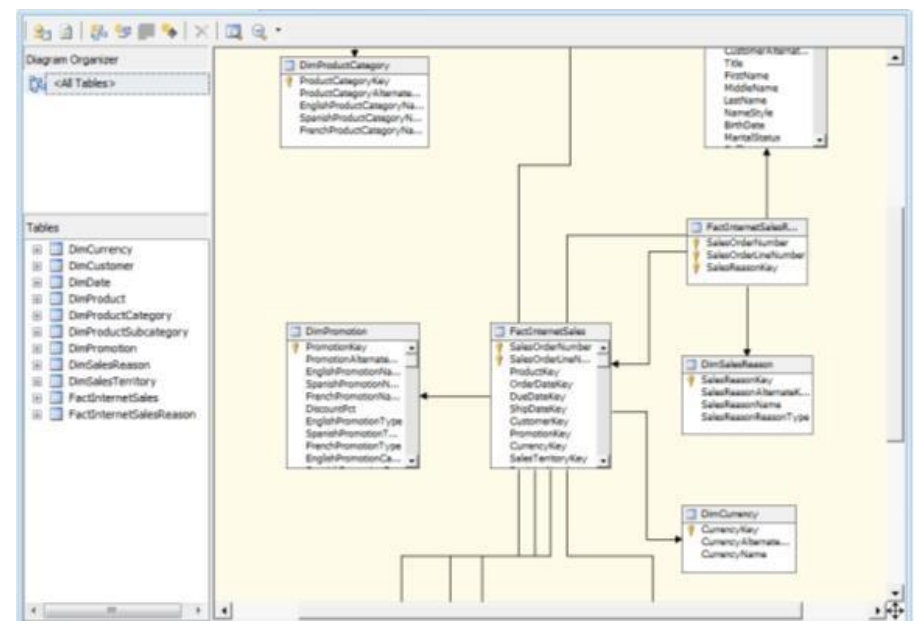

Figure 4 ETL Dataflow Diagram

\section{Conclusions and Suggestions}

The basic BI module for SMEs in the Manufacturing Industry Sector is Business Intelligence Analytics which has links with modules with ERP systems on: Sales and distribution (production), production planning that has benefits for SMEs as analytical applications, namely applications that provide processes decision making with time-based access from various data sources.

a) SMEs can use Business Intelligence to access a dimension of sales, production, and procurement data in an interactive data warehouse by utilizing OLAP to process slice and dice, drilling up and drilling down.

b) Whereas the second module is Business Intelligence Dahsboard / Reporting which deals with modules on ERP systems in: Sales and Distribution (sales), Production Planning (production) with Dashboard functions as one of the categories of Business Intelligence applications that are in real time to see the conditions of sales, production, and procurement of various information needed by SMEs in various kinds format that allows SMEs to make smart decisions quickly

Some things need to be considered before BI development is carried out, including the following two things that must be implemented immediately are:

a) Developing technology and information architectures that will become the basis of overall system and application development (including BI) and perfecting the entire database so that it is standardized and integrated (based on Enterprise Resource Planning / ERP). 
b) Form a development team that is obliged to prepare a mature and user-oriented plan. The existence of this team must also be followed by a change management process and knowledge transfer, so that the system can be implemented throughout the company

\section{Bibliography}

[1] Botta-Genoulaz, V. \& Millet, P.-A. (2006): An Investigation into the Use of ERP Systems in the Service Sector, International Journal of Production Economics, 99, pp. 202-221

[2] Esteves, J., and Pastor, J.: Enterprise Resource Planning Systems Research: An Annotated Bibliography, Communication of the Association for Information Systems (7:8) 2001.

[3] Inmon, W.H. 2005: Building the Data Warehouse, 4th edition, John Wiley \& Sons Inc. USA.

[4] K. Kumar, J. Van Hillegersberg: ERP experiences and evolution, in Communications of the ACM, vol. 43, no. 4, 2000, pp. 23.

[5] Kusnawi 2010: Multidimensional Data Warehouse dengan menggunakan MySQL, http://portalgaruda.org (April 2014) 